\title{
GAMIFICAÇÃO E INTERPRETAÇÃO AMBIENTAL: Uma Experiência em Trilha Ecológica
}

\author{
Diego Marques da Silva-Medeiros ${ }^{1}$ \\ Álvaro Lorencini Júnior ${ }^{2}$
}

\begin{abstract}
RESUMO
Este é o relato de uma pesquisa sobre as influências da gamificação na Interpretação Ambiental (IA). Questionamos qual seria a influência da gamificação nas trilhas interpretativas tradicionalmente realizadas em um parque ecológico. $O$ objetivo foi investigar tal influência e, para isso, buscamos desenvolver uma prática de intervenção que mantivesse o conteúdo dos discursos tradicionalmente proferidos pelos guias do local, mas que inovasse os métodos didático-pedagógicos a partir da gamificação. Os resultados mostraram que a atividade gamificada promoveu maior engajamento e participação, além de ter estimulado comportamentos objetivados pela atividade em uma maior proporção que na atividade tradicional. Concluímos que a gamificação pode trazer benefícios para a motivação do público participante em atividades de Interpretação Ambiental. Palavras-chave: Educação ambiental. Análise do comportamento. Análise de conteúdo. Análise textual discursiva.
\end{abstract}

\section{GAMIFICATION AND ENVIRONMENTAL INTERPRETATION: AN EXPERIENCE IN ECOLOGICAL TRAIL}

\section{ABSTRACT}

This is the report of a research on the influences of gamification in Environmental Interpretation. We questioned the influence of gamification on the interpretive trails traditionally carried out in an ecological park. The objective was to investigate this influence and, for this, it was sought to develop an intervention practice that maintained the content of the speeches traditionally uttered by the local guides, but that innovated the didactic-pedagogical methods from the gamification. The results showed that the gamified activity promoted greater engagement and participation of the participants, besides stimulating behaviors objectified by the activity in a greater proportion than in the traditional activity. It was concluded that gamification can bring benefits to the motivation of the public participating in Environmental Interpretation activities.

Keywords: Environmental education. Behavior analysis. Content analysis. Discursive textual analysis.

Recebido em: 17/9/2019

Aceito em: 7/12/2019

\footnotetext{
1 Professor de Prática de Ensino e Estágio Supervisionado da Faculdade de Ciências Biológicas e Ambientais (FCBA) da Universidade Federal da Grande Dourados (UFGD). Licenciado e Bacharel em Ciências Biológicas pela Universidade Estadual de Londrina (UEL). Especialista em Análise e Educação Ambiental em Ciências da Terra pela UEL. Mestre e doutor em Ensino de Ciências e Educação Matemática pela UEL. http://lattes.cnpq.br/4147363074561074. https://orcid.org/0000-0001-6660-1245. diegomarques@ufgd.edu.br

2 Licenciado e bacharel em Ciências Biológicas pela Faculdade de Educação e Instituto de Biociências da Universidade de São Paulo (USP São Paulo). Mestrado e Doutorado em Educação, área de Didática pela Faculdade de Educação da USP (Feusp). Professor do Departamento. de Biologia Geral do Centro de Ciências Biológicas da Universidade Estadual de Londrina (UEL/PR). Professor e orientador do Programa de Pós-Graduação: Mestrado e Doutorado em Ensino de Ciências e Educação Matemática da UEL e do Programa de Pós-Graduação: Mestrado e Doutorado em Educação para a Ciência e Matemática da Universidade Estadual de Maringá (UEM/PR). Coordenador do Grupo de Estudos e Pesquisa: Tendências e Perspectivas do Ensino das Ciências (Getepec). http://lattes.cnpq.br/0858496742334845. alvarojr@uel.br
} 
Experiências práticas e em pesquisas no Parque Estadual Mata dos Godoy -PEMG - (Londrina, PR) levaram-nos a identificar um problema a ser investigado. Impressões das experiências e dados produzidos em pesquisas realizadas entre os anos de $2010 \mathrm{e}$ 2012 - descritas em Silva $(2011,2012)$ - mostraram que parte dos jovens, em visitas escolares, não se mantinha suficientemente engajada, do começo ao fim, nas atividades de Interpretação Ambiental ${ }^{3}$ em trilhas ecológicas do PEMG. De fato, muitos desses estudantes pareciam não se interessar ou perder o interesse pela prática educativa guiada no Parque em meio ao percurso - algo que observamos inúmeras vezes e que aparecia como conteúdo de reclamação de guias do Parque, que enfrentavam a situação.

No intuito de resolver o problema identificado nas práticas de Interpretação Ambiental do PEMG, pesquisamos sobre métodos alternativos que pudessem aumentar a qualidade motivacional da atividade realizada com os jovens visitantes. Encontramos um método atual que vem ganhando relevância no contexto educacional: a gamificação que, de acordo com Beza (2011 , p. 4), trata-se do uso de "mecanismos dos jogos em atividades comuns (não jogos) no sentido de influenciar o comportamento das pessoas" (tradução nossa). Assim, a gamificação busca aproveitar a força motivacional dos jogos em situações que necessitem engajamento das pessoas em problemas do mundo "normal" (não gamificado) (LEE; HAMMER, 2011). No que se refere à educação, pode-se afirmar que usar elementos de jogos em atividades de ensino teria a função de aumentar o engajamento dos aprendizes em atividades propostas pelos educadores (KAPP, 2012).

A Interpretação Ambiental é uma atividade que pode ser motivadora a indivíduos que mantêm atitudes e sentimentos positivos em relação a ela e aos ambientes naturais. Muitas pessoas gostam de caminhar junto a natureza; outras, além disso, dizem sentir prazer em aprender sobre aquilo que observam; há, inclusive, aqueles que chegam a se engajar em ações de conservação do meio ambiente visitado. Existe, contudo, quem não tem essas características, cujas preferências são outras, mas que, em um contexto mais amplo de crises ambientais e à luz da Educação Ambiental e seus propósitos, necessitam se engajar em atividades que auxiliem no desenvolvimento de compreensões, atitudes, responsabilidades e competências relevantes à formação da cidadania ambiental - objetivos, esses, da Educação Ambiental (SMITH, 2006) - como é o caso da Interpretação Ambiental e de trilhas ecológicas.

Essas necessidades formativas vêm do movimento da Educação Ambiental e compõem, inclusive, o Programa Nacional de Educação Ambiental (Pronea) (BRASIL, 2005) e as bases, os parâmetros e as diretrizes oficiais para o ensino formal e obrigatório no Brasil (PCNs) (BRASIL, 1998, 2013, 2017). As escolas, por exemplo, costumam organizar excursões com turmas de alunos para sítios de Interpretação Ambiental. Nesse caso, é

\footnotetext{
3 De acordo com Silva-Medeiros e Haydu (2018, p. 45), a Interpretação Ambiental é uma atividade que tem como meta "que o público aprenda sobre os lugares visitados com prazer e responsabilidade, de forma que a visita se torne recreativa, educativa e ecologicamente sustentável [e tem como objetivo] a compreensão, a sensibilidade e a responsabilidade do indivíduo para com o patrimônio vivenciado no momento da visitação. [...]. Metodologicamente, na Interpretação Ambiental os intérpretes ambientais agem de forma a preparar o ambiente a ser visitado no âmbito físico e discursivo, com a meta de torná-lo um evento capaz de garantir a disciplina, a atenção e a reflexão do indivíduo no momento da visitação.

4 Esses objetivos são tratados com mais ênfase e à luz de princípios e conceitos da Análise do Comportamento em Silva-Medeiros e Haydu (2018).
} 
notável a relevância de que os meios pelos quais a atividade ocorre devam promover estratégias, as mais seguras possíveis, para a manutenção do engajamento do visitante do começo ao fim da atividade, principalmente ao se levar em consideração que, como já referido, o nível de interesse prévio dos participantes para com as nuances da atividade pode variar de indivíduo para indivíduo.

Formulamos, então, a hipótese de que a gamificação poderia compor uma relevante ferramenta a ser mobilizada no planejamento de atividades de Interpretação Ambiental, pois, se os elementos intrínsecos à atividade não são capazes de estimular o engajamento de uma parcela da audiência jovem, então, talvez, elementos de jogos possam desempenhar esse papel até que, e contribuindo para que, as atitudes pró-ambientais relevantes a esse fim sejam desenvolvidas.

Questionamos, portanto, qual seria a influência da gamificação nas trilhas interpretativas do PEMG. Assim, o objetivo foi investigar tal influência e, para isso, buscamos desenvolver uma prática de intervenção que mantivesse o conteúdo dos discursos tradicionalmente proferidos pelos guias do local, mas que inovasse os métodos didático-pedagógicos a partir da gamificação. Consequentemente, desenvolvemos uma atividade gamificada de Interpretação Ambiental denominada "Expedição ao Meio Ambiente" (EMA), ${ }^{5}$ que foi aplicada em experiências no PEMG. Neste trabalho relatamos como se deram essas experiências e como foi realizada a investigação, seus resultados, discussões e conclusões a que pudemos chegar.

\section{GAMIFICAÇÃO DA INTERPRETAÇÃO AMBIENTAL}

A atividade gamificada EMA foi desenvolvida tomando-se como base referenciais de quatro campos do conhecimento: o da Educação Ambiental, o da Interpretação Ambiental, o da gamificação e o da Análise do Comportamento. Partindo da ideia contida em Zabala (1998), de que há quatro fontes de conhecimento que embasam a prática educativa - a saber, a sociológica, a psicológica, a epistemológica e a metodológica - o desenvolvimento da EMA teve como fonte sociológica o objetivo proposto pelo Pronea (BRASIL, 2005) de formar cidadãos para uma sociedade socialmente justa e ecologicamente sustentável. Para tal, formulamos objetivos educacionais que auxiliassem no desenvolvimento da cidadania ambiental. Tais objetivos foram embasados nas categorias apresentadas por Smith (2006) e interpretadas à luz dos princípios da Análise do Comportamento por Silva-Medeiros e Haydu (2018), a saber: compreensão ambiental, sensibilização ambiental, responsabilização ambiental e formação de competências ambientais.

De modo geral, embasando-se em Smith (2006), levando em consideração o que é exposto em Silva-Medeiros e Haydu (2018) e tomando-se como base os tipos de conteúdo da prática educativa apresentados e discutidos em Coll et al. (2000), é possível afirmar que: compreensão ambiental está relacionada ao desenvolvimento factual e conceitual do conhecimento do sujeito em relação à natureza e suas nuances; sensibilização ambiental é relativa ao desenvolvimento de atitudes, sentimentos e juízos de

Descrição completa da atividade em Silva-Medeiros (2016a , 2016b). 
valor alinhados à conservação ambiental; responsabilização ambiental é o desenvolvimento tanto de compreensões quanto de sensibilidades especificamente relacionadas às relações e interações do ser humano com a natureza e o meio ambiente; competências ambientais são procedimentos, habilidades, métodos e estratégias que tornam tais relações e interações sustentáveis, e cidadania ambiental trata-se da mobilização dessas compreensões, sensibilidades, responsabilidades e competências no efetivo agir em prol da conservação do meio ambiente.

Dos objetivos sociológicos mais gerais para os quais planejamos a EMA, foi possível estabelecer os objetivos mais específicos, traduzidos em conteúdo de ensino e aprendizagem. Tal conteúdo teve relação de equivalência com aquele que era tradicionalmente mobilizado pelos guias do PEMG e que pôde ser identificado, descrito e interpretado em Silva (2011, 2012).

Como fonte psicológica, mobilizamos conhecimentos provindos da Análise do Comportamento, que é um campo filosófico, de pesquisa e de intervenção em que as ações (respostas) dos organismos - sejam públicas ou privadas - são tidas como variáveis dependentes, enquanto os estímulos do ambiente (antecedentes ou consequentes) são variáveis independentes (CHIESA, 1994). Suas contribuições principais para o trabalho estiveram relacionadas com a compreensão das relações de contingência que desenvolvem e mantêm o comportamento humano e com os conceitos de "regra" e "controle comportamental".

Motivar os sujeitos a se engajarem e manterem o interesse em tarefas que não Ihes garantem consequências reforçadoras imediatas não é algo simples. Na escola, os professores usam de estímulos arbitrários, tais como notas, elogios e promessas de utilidade futura do conhecimento. Por vezes, adotam estímulos aversivos, como reprovações e castigos. A profissão também nem sempre é motivadora por si só e o engajamento é controlado pelo salário regular no fim do mês ou pela comissão proporcional à produtividade. De acordo com Baum (1999), entretanto, o ser humano tem a capacidade de aprender o autocontrole, o que torna seu comportamento menos sensível a consequências imediatas e sob o controle de reforçadores de médio e longo prazos.

Em conformidade com Skinner (2003), consequência reforçadora é aquela que aumenta a frequência de ocorrência do comportamento que a gerou por, de alguma maneira, ser "apetitosa" ao organismo ou o livrar de situações adversas. As ações dos indivíduos provocam mudanças no ambiente, o que é chamado de consequências. Tais ações também ocorrem em determinados contextos e, quando geram consequências reforçadoras, os elementos desses contextos (aos quais o indivíduo esteve sensível) ficam marcados como estímulos que discriminam (estímulos discriminativos) as situações em que ocorreram as consequências de suas ações. Desse modo, na presença de estímulos discriminativos, é mais provável que o indivíduo volte a agir de maneira semelhante às ações anteriormente reforçadas. O comportamento, nesse caso, é formado por uma tríplice contingência entre a ação do organismo (resposta), seu contexto (estímulo discriminativo) e a consequência gerada por meio dessa ação (podendo ou não ser reforçadora). 
Baum (1999) explica que, quando em situações que geram consequências reforçadoras apenas a médio e longo prazo, o autocontrole necessário para que o indivíduo se engaje a elas ocorre, no ser humano, por meio de autorregras. Regras são verbalizações que descrevem comportamentos em termos de relações de contingência entre contextos, ações e consequências possíveis - por exemplo, dizer que o indivíduo que sair da trilha demarcada (ação) em atividades de Interpretação Ambiental (estímulo discriminativo) corre o risco de se machucar (consequência). Ao indivíduo verbalizar sobre seu próprio comportamento (autorregra), ocorre um aumento na probabilidade de esse comportamento ficar sob o controle de consequências menos imediatas e que, desse modo, não seriam fortes estímulos ao comportamento sem as autorregras (MATOS, 2001). Há, no entanto, situações em que o comportamento do indivíduo, por algum motivo, continua a ser controlado por consequências mais imediatas, levando-o a se engajar em tarefas que lhe trarão consequências adversas em médio e longo prazos, ou deixando de se engajar em tarefas potencialmente importantes para o futuro, mas que não apresentam consequências reforçadoras em curto prazo. Também há a alternativa de que o tempo disponível para se engajar em determinada tarefa importante ao indivíduo seja relativamente curto, a ponto de não haver condições de aprender autorregras e de desenvolver o controle delas sobre o próprio comportamento - como no caso da escola, em que nem sempre há tempo ou o professor consegue convencer o aluno sobre a importância futura da matéria. Nesses casos, faz-se o uso de consequências arbitrárias ou estimula-se comportamentos automaticamente reforçados (explicação adiante).

Consequências intrínsecas ou naturais do comportamento são aquelas que ocorrem sem que alguém as planeje. Consequências arbitrárias ou artificiais são planejadas e, por vezes, intencionalmente aplicadas no intuito de reforçar ou punir ${ }^{6}$ determinado comportamento (BAUM, 1999). Assim sendo, quando se pretende que o indivíduo se engaje em determinada tarefa cuja consequência reforçadora não parece exercer controle sobre seu comportamento, aplicam-se reforçadores arbitrários. Do contrário, quando se quer que o indivíduo abandone determinado engajamento, retira-se a possibilidade de contato com consequências reforçadoras ou aplica-se consequências punitivas. Alguns comportamentos, no entanto, podem ser automaticamente reforçados, como quando o indivíduo consegue operar com sucesso (de acordo com suas intenções declaradas) o meio (SKINNER, 2003). Nesse caso, outra estratégia cabível ao engajamento do sujeito em tarefas que não parecem gerar reforçadores imediatos seria aumentar a estimulação de comportamentos automaticamente reforçados nas situações que envolvem a tarefa.

Como já mencionado anteriormente, porém, agora fazendo o uso de termos da Análise do Comportamento, a Interpretação Ambiental é uma atividade que traz reforços imediatos a muitos indivíduos que mantêm, em seus repertórios comportamentais, atitudes e sentimentos positivos em relação à atividade. Existem, contudo, aqueles cuja participação na atividade não é reforçada, mas que podem aprender as atitudes e sentimentos importantes para tal, caso se mantenham engajados nela. É nesse sentido que

Punição, ao contrário de reforço, é a função da consequência em diminuir a frequência do comportamento que a gerou. 
a gamificação ganha importância, pois traz elementos de jogos que podem servir como reforçadores arbitrários e provisórios, até que os reforçadores naturais e intrínsecos da Interpretação Ambiental possam controlar o engajamento do sujeito na atividade.

Como fonte metodológica do desenvolvimento didático da EMA, portanto, a gamificação teve um relevante papel, principalmente no que se refere à definição de uma série de metas pedagógicas que, por sua vez, serviram de base para o desenvolvimento das atividades didáticas. Essas metas tiveram como referência o trabalho de Morford et al. (2014), em que os autores se basearam nos elementos da gamificação expostos por Deterding et al. (2011) para proporem comportamentos de jogar, ou seja, padrões em termos comportamentais que servem de indicadores para inferir se um indivíduo está jogando ou se está respondendo a elementos que funcionam na manutenção de seu comportamento de jogar. Nesse sentido, Morford et al. (2014) indicam seis categorias de comportamentos de jogar que, no intuito de estabelecerem maior correlação com princípios e conceitos da Análise do Comportamento, tiveram suas descrições interpretadas da seguinte maneira:

a. Impacto direto nos efeitos e resultados do jogo: as respostas do indivíduo e as magnitudes delas no jogo afetam diretamente as características dos resultados ou de seus processos de obtenção.

b. Clareza quanto aos objetivos ou às condições de término do jogo: os comportamentos do indivíduo são controlados pelos resultados necessários ao avanço progressivo do jogo e pela previsão do encerramento das tarefas.

c. Controle de regras e barreiras: os comportamentos do indivíduo são controlados por descrições, a priori, de estímulos discriminativos e de consequências de seus comportamentos no jogo ou são limitados por elementos a serem descobertos.

d. Ser sensível a eventos probabilísticos: os comportamentos do indivíduo são controlados por possibilidades diversas, de modo que as consequências de suas ações no jogo possam ser inferidas (autorregras), mas com algum grau de incerteza.

e. Ser estimulado a desenvolver estratégias: para que os objetivos do jogo continuem sendo atingidos, o comportamento do indivíduo deve se alterar conforme seu progresso ou autorregras devem ser desenvolvidas para controlar o comportamento do jogador.

f. Jogar livre de persuasão: o engajamento nos comportamentos anteriormente descritos não pode ser mantido por encorajamento social ou coação, mas, apenas, controlado por fatores intrínsecos ao jogo.

Sobre "jogar livre de persuasão", Morford et al. (2014) também descrevem elementos que podem servir de estímulo à manutenção do comportamento de jogar. São eles: novidades ou características do jogo a serem incrementadas conforme a progressão do jogador, com destaque especial para os reforços a serem apresentados; interações com outros jogadores, dos tipos "cooperativas" e "competitivas", porém o segundo tipo pode funcionar num sentido contrário se não houver um controle adequado das contingências, diminuindo a frequência de respostas de jogar em indivíduos repetida- 
mente malsucedidos ou, até mesmo, deixando de ser algo desafiador e, assim, motivador a indivíduos repetidamente bem-sucedidos; necessidade de desenvolver estratégias que, na medida adequada, possuem caráter desafiador e, portanto, motivador, e histórias, que podem trazer elementos novos (novidades) ou serem apenas tramas comuns do cotidiano (serious games, por exemplo), por meio de histórias reais, baseadas em fatos reais, fictícios ou fantasiosos.

Estratégias didáticas que estimulam os indivíduos a emitirem os comportamentos de jogar descritos por Morford et al. (2014) e que os fazem responder aos elementos que estimulam a manutenção desses comportamentos podem ser consideradas estratégias gamificadas e, dessa maneira, funcionam na motivação e manutenção do engajamento dos indivíduos em atividades educativas, tais quais as que ocorrem em situações de Interpretação Ambiental.

O embasamento teórico do desenvolvimento da EMA foi, portanto, efeito dos objetivos da Educação Ambiental descritos no Pronea (BRASIL, 2005) e em Smith (2006) como fonte sociológica; do conteúdo de ensino tradicionalmente abordado por guias do PEMG, descritos em Silva (2011, 2012), como fonte epistemológica; da Análise do Comportamento como fonte psicológica e da Interpretação Ambiental associada à gamificação da educação como fonte metodológica.

\section{GAMIFICAÇÃO NO PEMG}

A Interpretação Ambiental no PEMG tradicionalmente ocorria tendo as trilhas interpretativas como as principais atividades. Os participantes eram, normalmente, turmas escolares que visitavam o Parque, visitantes convidados em eventos especiais e visitantes casuais de diversos perfis. As turmas escolares representavam o maior volume relativo de visitas ao parque e eram compostas, principalmente, por estudantes de Ensino Fundamental e professores.

A chegada dos visitantes ao Parque ocorria em um estacionamento ao lado do Centro de Visitantes (CV), para onde eles eram primeiramente encaminhados. Nesse CV havia materiais expostos que representavam os recursos naturais, culturais e históricos do Parque, além de uma sala na qual era reproduzido um vídeo sobre as Unidades de Conservação do Paraná e sobre a visitação nesses locais.

Após o CV, os visitantes eram encaminhados ao início das trilhas, nas quais se realizava a Interpretação Ambiental guiada. A atividade nas trilhas durava entre 60 e 90 minutos e a estratégia didática se resumia em realizar paradas em pontos específicos da trilha, quando mensagens interpretativas eram ditas de modo oral pelos guias aos visitantes.

Pesquisas realizadas no PEMG e descritas em Silva $(2011,2012)$ identificaram o conteúdo das mensagens dos intérpretes aos visitantes do Parque, o que possibilitou que pudéssemos trabalhar na inovação da Interpretação Ambiental realizada no local a partir de elementos da gamificação. Nosso trabalho deu origem à atividade gamificada denominada Expedição ao Meio Ambiente. 
De maneira sumária, na EMA, os participantes são ambientados em uma história fictícia apocalíptica, em que a humanidade está prestes a desaparecer por problemas ambientais decorrentes da falta de conhecimento sobre os ecossistemas. Nessa história, os participantes tinham que, em equipes, munidos do material fornecido (Figura 1) e das funções que lhes eram atribuídas, realizar descobertas sobre o ambiente de sua expedição (no caso, o PEMG) (SILVA-MEDEIROS, 2016a, 2016b). Conforme realizam descobertas, são atribuídos pontos e conquistas à equipe, que colabora e compete com outras equipes que estão realizando a mesma atividade.

Figura 1 - Imagem do material recursivo da Expedição ao Meio Ambiente

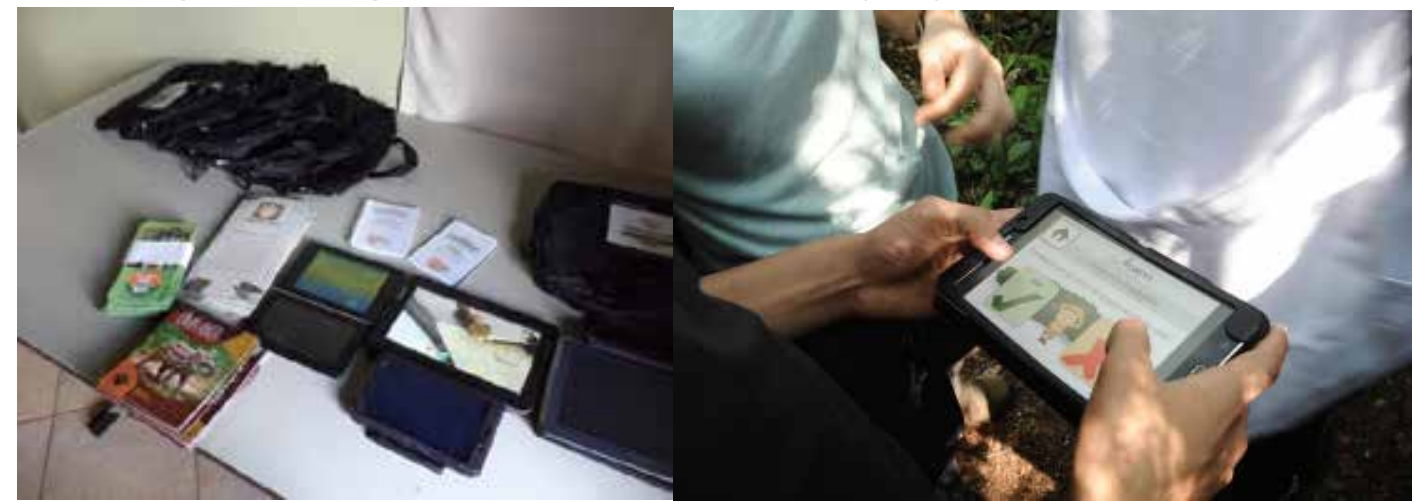

À esquerda, mobiles, livro de consultas, caderneta de anotações, bolsas com logotipo da atividade e cartilhas com informações sobre projetos da ONG Meio Ambiente Equilibrado no PEMG, faziam parte do material recursivo da EMA. À direita, os participantes operando o Sistema do Operador em uma das descobertas que estavam sendo realizadas.

Fonte: SILVA-MEDEIROS (2006b).

As equipes da EMA são formadas por entre três e cinco visitantes do Parque acompanhados por um guia do local. Aos participantes das equipes são atribuídas funções, a saber: Operador, Coletor e Naturalista, cada qual fazendo o uso de material específico para a realização da função que exerce. Assim, a equipe de participantes da EMA sai às trilhas unida, munida de equipamento específico e com o objetivo de realizar descobertas sobre aquilo que lhes despertar a curiosidade ou sobre o que o guia lhes apontar como sendo relevante de ser descoberto.

A partir do momento em que a equipe decide descobrir sobre algo, o primeiro a entrar em ação é o participante Operador. O objeto da descoberta pode ser algo relativo à natureza do lugar ou aos elementos antrópicos do Parque. Além disso, eles podem ser acessados pelos diversos sentidos ou pela abstração, destacando-se que os participantes podem, por exemplo, questionar sobre a história do Parque, sem que esse elemento esteja diretamente acessível aos sentidos.

Com acesso ao elemento a ser descoberto, o Sistema do Operador é acionado (Figura 2) e os participantes respondem a questões de múltipla escolha sobre o elemento, de modo a direcioná-los às informações da descoberta no sistema - algo semelhante às chaves de identificação da Biologia. 


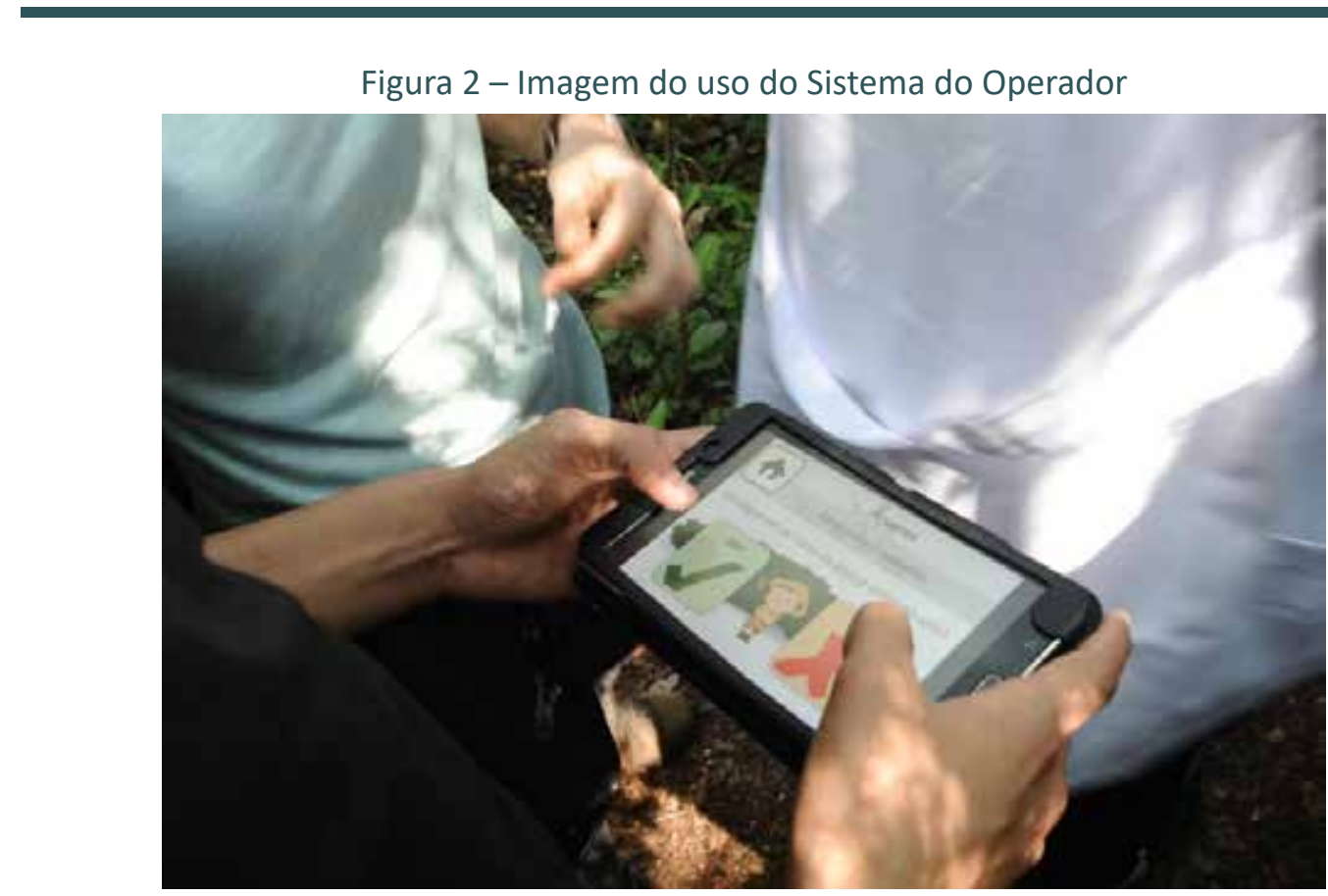

Os participantes lidam com um dos quadros de decisão do Sistema do Operador.

Fonte: Imagem capturada em ocasião do teste-piloto da EMA.

Quando todas as questões sobre um determinado elemento a ser descoberto são corretamente respondidas, o sistema fornece uma possível descoberta, com título e imagens para que o participante possa confrontar com o objeto real ao qual tem acesso. Em seguida, são fornecidos dois textos informativos sobre a descoberta: o primeiro cujo conteúdo estabelece relação com as características técnico-científicas do elemento da descoberta e outro relacionado à interação do ser humano para com o elemento em questão. Para concluir a descoberta e ser recompensada, a equipe deve, então, responder corretamente a duas questões sobre o elemento descoberto.

Como o processo de descobertas no sistema envolve diversos conceitos e termos técnico-científicos relativos a eles, o participante Naturalista leva consigo o Manual do Naturalista, composto por um glossário e uma enciclopédia que devem auxiliar nas compreensões e tomadas de decisão. Nesse mesmo Manual também estão presentes as normas e regras do jogo, que devem ser respeitadas e seguidas pelas equipes para que possam realizar a expedição. O Coletor, por sua vez, porta o Diário do Coletor, no qual registra todas as descobertas realizadas pela equipe e suas respectivas conquistas e pontuações. Ao final da atividade a equipe contabiliza seus pontos, se classifica em um nível de experiência e se estabelece em uma posição de ranking em relação às demais equipes participantes da EMA.

\section{PROCEDIMENTOS DA PESQUISA}

Os problemas ligados à prática de ensino e seus componentes psicossociais podem ser compreendidos pelas manifestações comportamentais de seus atores, tais como são as expressões verbais, seus enunciados e suas mensagens, que podem conter unidades de análise bastante relevantes à pesquisa educacional (FRANCO, 2008). Para a investigação de tais manifestações, a Análise de Conteúdo teve e ainda tem grande 
utilidade, observando-se que uma das principais obras sobre o método é de autoria de Laurence Bardin (1977). Para a autora, o método consiste em aplicar rigor às técnicas de investigação hermenêutica a partir de uma imersão do analista nos dados em um caminho árduo que vai da desconstrução à reconstrução do material pesquisado, o qual leva o nome de corpus da pesquisa. Dentro da tradição da Análise de Conteúdo, no entanto, podemos encontrar vários autores que se aventuram a abordar sobre o método, suas nuances, seus avanços e suas alternativas, tais como Moraes e Galiazzi (2007), que sugerem estratégias para análises no âmbito qualitativo. Por ser uma alternativa à Análise de Conteúdo, os autores denominaram o método de "Análise Textual Discursiva", que de maneira alguma é exaustivo, o que Ihe fornece um caráter complementar à Análise de Conteúdo. Assim, nesta pesquisa tomamos, como instrumento metodológico, a Análise de Conteúdo (BARDIN, 1977; FRANCO, 2008) associada à Análise Textual Discursiva (MORAES; GALIAZZI, 2007).

Franco (2008) relata que as pesquisas cujo instrumento metodológico vem sendo a Análise de Conteúdo das expressões verbais, nas últimas décadas, tenderam a aplicar estímulos para a emissão de comportamentos que são tomados como dados de análise. Para isso, o pesquisador lança mão de suas próprias ferramentas de produção de dados que, no caso desta pesquisa, foi o que se denominou EMA. A função da EMA na pesquisa foi, portanto, oportunizar a manifestação de comportamentos estimulados por elementos da gamificação, por elementos que funcionam na manutenção do comportamento de jogar e por mensagens tradicionalmente emitidas na Interpretação Ambiental realizada no PEMG. Em termos de comparação, no entanto, também foram produzidos dados a partir de registros de observação naturalística, de mínima interferência, de triIhas interpretativas tradicionalmente realizadas no Parque (não gamificadas).

Os registros feitos em ambos os casos (trilha tradicional e trilha gamificada) ocorreram com o auxílio de gravador de som, útil principalmente para o registro dos comportamentos verbais orais dos participantes. Outras formas de expressão eram registradas por meio de notas em caderno de campo e câmera fotográfica pelo pesquisador analista, que se fez sempre presente.

A atividade tradicional foi realizada iniciando-se pela apresentação do vídeo já citado e, em seguida, os participantes foram guiados pelas trilhas do Parque em um percurso que durou 73 minutos, com paradas estratégicas do guia em pontos para a abordagem discursiva planejada (oral, em todos os casos). A atividade dos participantes foi bastante passiva, de modo que o guia cobrava apenas o seguimento de regras de conduta, a atenção e, por vezes, realizava uma ou outra pergunta. Nesse caso, as expressões verbais dos participantes foram registradas por um gravador de som, do comprimento de uma caneta e largura de aproximadamente três centímetros, pendurado no pescoço e posicionado em contato com o tórax do guia, à vista da audiência. O pesquisador acompanhou passivamente a atividade, registrando apenas anotações e imagens. 
A atividade gamificada com a EMA teve início a partir da apresentação do material (Figura 1) e regras da atividade ${ }^{7}$ no Centro de Visitantes do PEMG e durou 101 minutos nas trilhas. Sendo seu caráter autoguiado, não houve o acompanhamento tradicional por guias do Parque, apenas pelo pesquisador, que teve a mesma função que um guia treinado na EMA, a saber: lançar mão de estratégias para controlar o comportamento dos visitantes no que diz respeito ao seguimento de regras, instruções e barreiras da atividade e do Parque; não definir caminhos a seguir e pontos a parar (como é de ocorrência tradicional no PEMG) tendo, os participantes, liberdade de escolha nesse sentido, desde que obedecessem às regras, instruções e barreiras da atividade e do Parque, e sugerir pontos de parada e descobertas de objetos e relações que tradicionalmente ocorrem na abordagem interpretativa do PEMG.

Foi realizado registro sonoro da atividade por meio do aplicativo "Easy Voice Recorder Pro", desenvolvido pela Digipom, que rodava em plano de fundo, de modo imperceptível aos participantes, em um tablet (mobile). O mobile compunha um dos materiais da EMA (ver Figuras 1 e 2) que rodava, em primeiro plano, o Sistema do Operador, cuja função era, como já explicado anteriormente, a de chegar às informações acerca de uma determinada descoberta sobre o ambiente visitado.

Os sujeitos participantes da pesquisa foram alunos de 8 ㅇ e 90 anos do Ensino Fundamental da rede pública do município de Londrina. A escolha do perfil dos participantes justificou-se nos PCNs do Ensino Fundamental (BRASIL, 1998, p. 87), cuja informação é a de que os estudantes que estão nessa etapa da educação formal podem apresentar repertório comportamental para estabelecer "relações complexas e detalhadas entre diferentes elementos em estudo". Além disso, mostram-se mais autônomos diante das formas de trabalho, apresentando boa capacidade de formalizar o pensamento na linguagem, de compreensão das definições científicas, na obtenção e organização de dados e na construção de hipóteses. Há também maior probabilidade de apresentarem "interesse em compreender o alcance social e histórico das diferentes atividades humanas" (loc. cit.). Determinamos, portanto, que estudantes de etapas anteriores ou posteriores ao quarto ciclo do Ensino Fundamental não seriam adequados à pesquisa. Os primeiros, pois poderiam apresentar certa dificuldade na lida mais autônoma com as tarefas da EMA; os segundos, pois seria relevante que ainda não tivessem entrado em contato com muitos dos temas da abordagem, para que se pudesse evidenciar, com mais facilidade, momentos de aprendizagem inédita e suas decorrentes dificuldades como no caso da classificação sistemática dos seres vivos, aprendizado que normalmente ocorre no Ensino Médio.

Para a trilha tradicional foi selecionada uma turma de 10 participantes que visitaram o PEMG por meio de agendamento direto com o Parque e sem quaisquer pretensões de participarem da pesquisa. Ao chegarem, o pesquisador se apresentou e foi concedida a autorização dos participantes para serem gravados no decorrer da atividade. Por outro lado, para a trilha gamificada, a atividade foi associada ao evento do Dia

Reitera-se que os pormenores da atividade gamificada EMA, como sua dinâmica, suas regras e seus materiais, estão devidamente apresentados em Silva-Medeiros (2016a , 2016b). Este artigo propõe apenas relatar a pesquisa desenvolvida tendo a EMA como instrumento metodológico. 
da Árvore promovido pela ONG Meio Ambiente Equilibrado (MAE), em que as escolas estavam cientes de que os alunos participariam de um método inovador e de que suas expressões verbais seriam registradas e analisadas com fins acadêmicos. De todas as escolas participantes, foi escolhida, por meio de sorteio, uma turma de três participantes. Importa frisar que a diferença numérica de participantes entre as atividades tradicional e gamificada decorreu do fato de que a primeira era planejada para conter até 12 participantes enquanto a segunda, entre 3 e 5.

Para formar o corpus da pesquisa os registros sonoros foram transcritos com foco nos comportamentos verbais orais dos participantes das atividades. Comportamentos verbais orais de outros sujeitos, como o professor da turma e o guia da atividade, assim como detalhes de acontecimentos que não puderam ser capturados pelo gravador, foram apenas narrados quando em relação aos comportamentos dos participantes. 0 corpus, portanto, foi composto por um texto de narrativa, de autoria do pesquisador, com base nas transcrições dos dados sonoros, com acréscimo das anotações realizadas durante sua participação nas atividades.

Uma primeira leitura do corpus possibilitou confirmar a adequação com o referencial teórico e os objetivos da pesquisa, dando origem a três metas de análise: evidenciar em termos qualitativos e quantitativos (a) se os participantes da atividade gamificada, sensíveis aos seus elementos de gamificação, emitiram os comportamentos de jogar, embasando-se em Morford et al. (2014), (b) se os participantes da atividade gamificada emitiram comportamentos e responderam aos elementos relevantes à manutenção do comportamento de jogar, baseando-se em Morford et al. (2014), e (c) se comportamentos verbais relacionados aos objetivos da Educação Ambiental e da Interpretação Ambiental foram mobilizados por participantes ao longo da atividade gamificada de Interpretação Ambiental em trilhas, embasando-se em Smith (2006). Cada uma das metas deu origem a um índice amplo de análise, a saber: (a) comportamentos de jogar; (b) manutenção dos comportamentos de jogar e (c) objetivos da Educação e da Interpretação Ambiental.

Na sequência, fundamentando-se na Análise do Comportamento, foram definidos os indicadores de análise a partir de critérios relacionados aos estímulos discriminativos, às consequências e à topografia ${ }^{8}$ das ações dos participantes da pesquisa. 0 Quadro 1 apresenta a relação completa dos índices de análise que fundamentaram a desconstrução do corpus em unidades de registro (unitarização) e a formação de categorias.

\footnotetext{
8 Em Análise do Comportamento, topografia se refere apenas à aparência estética do comportamento, e não à sua função. Por motivos culturais, no entanto, é possível deduzir, com certo nível de precisão, as relações de contingência que envolvem determinados comportamentos. Xingar uma pessoa, por exemplo, é uma resposta cuja probabilidade é alta para consequências punitivas em determinados contextos mais formais, mas não em outros, por exemplo, quando se xinga o juiz da partida a partir de uma arquibancada em uma partida de futebol. Nesse último caso o comportamento pode até ser reforçado pelo comportamento dos outros torcedores.
} 


\begin{tabular}{|c|c|c|}
\hline \multicolumn{3}{|c|}{ Quadro 1 - Índices de análise da pesquisa e suas codificações categóricas } \\
\hline \multirow{6}{*}{\multicolumn{2}{|c|}{$\begin{array}{l}\text { Comportamento de jogar } \\
\text { (Categoria 1) }\end{array}$}} & $\begin{array}{c}\text { Impacto direto nos efeitos e resultados da atividade } \\
\text { (Subcategoria } 1 \mathrm{~A})\end{array}$ \\
\hline & & $\begin{array}{l}\text { Clareza quanto a objetivos, metas e condições de término } \\
\text { da atividade (Subcategoria 1B) }\end{array}$ \\
\hline & & $\begin{array}{c}\text { Controle de regras, instruções e barreiras da atividade } \\
\text { (Subcategoria 1C) }\end{array}$ \\
\hline & & $\begin{array}{c}\text { Sensibilidade a eventos probabilísticos da atividade } \\
\text { (Subcategoria 1D) }\end{array}$ \\
\hline & & $\begin{array}{c}\text { Estimulação no desenvolvimento de estratégias para a } \\
\text { atividade (Subcategoria } 1 \mathrm{E} \text { ) }\end{array}$ \\
\hline & & Início livre de persuasão na atividade (Subcategoria 1F) \\
\hline \multirow{4}{*}{\multicolumn{2}{|c|}{$\begin{array}{c}\text { Manutenção do comportamento } \\
\text { de jogar } \\
\text { (Categoria 2) }\end{array}$}} & $\begin{array}{c}\text { Sensibilidade a elementos novidadeiros da atividade } \\
\text { (Subcategoria 2A) }\end{array}$ \\
\hline & & Interação interpessoal (Subcategoria 2B) \\
\hline & & Evolução de estratégias em curso (Subcategoria 2C) \\
\hline & & História da atividade (Subcategoria 2D) \\
\hline \multirow{5}{*}{$\begin{array}{c}\text { Objetivos } \\
\text { da Educação } \\
\text { Ambiental } \\
\text { (Categoria 3) }\end{array}$} & \multirow{5}{*}{$\begin{array}{l}\text { Objetivos da } \\
\text { Interpretação } \\
\text { Ambiental } \\
\text { (Categoria 3') }\end{array}$} & Compreensão ambiental (Subcategoria 3A) \\
\hline & & Sensibilidade ambiental (Subcategoria 3B) \\
\hline & & Responsabilidade ambiental (Subcategoria 3C) \\
\hline & & Competência Ambiental (Subcategoria 3D) \\
\hline & & Cidadania Ambiental (Subcategoria 3E) \\
\hline
\end{tabular}

As células escurecidas representam a categoria que foi criada em paralelo à Categoria 3, para representar os objetivos específicos da Interpretação Ambiental.

Fonte: SILVA-MEDEIROS (2016b).

A unitarização do corpus ocorreu a nível semântico e os limites temáticos das unidades de registro foram definidos de acordo com a relação funcional dos dizeres dos participantes com seus estímulos antecedentes e, por vezes, fatores consequentes destacando-se que algumas dessas relações funcionais foram deduzidas com base no valor cultural da topografia dos comportamentos. A partir dos indicadores que as unidades de registro continham, elas foram, então, indiciadas e, consequentemente, categorizadas em dois níveis categóricos denominados Categoria e Subcategoria - sendo formados a priori e com base nos índices de análise e suas nuances (apresentadas na seção anterior). Importa ressaltar também que as categorias não foram formadas de modo excludente entre si, podendo uma mesma unidade de registro ter sido indiciada em uma ou mais categorias concomitantemente.

Além das unidades de registro, foram também segmentadas unidades de contexto relacionadas a cada momento específico da atividade, o que serviu para dar significado às unidades de registro e para evidenciar a qualidade e a quantidade de comportamentos dos participantes no decorrer da trilha. Em relação aos objetivos da pesquisa importou, em primeiro lugar, identificar a ocorrência das categorias no corpus, no entanto a proporção dessa ocorrência foi igualmente relevante, uma vez que a proposta da gamificação seria a de elevar ou, ao menos, manter o nível de motivação para a emissão dos comportamentos analisados em relação às atividades tradicionais de Interpretação Ambiental em trilhas. Desse modo, caracterizou-se a pesquisa como de caráter qualiquantitativo. 


\section{RESULTADOS E DISCUSSÃO}

Do que foi possível vislumbrar a partir das categorias formadas na análise, um dos mais significativos resultados para com o objetivo da pesquisa foi a frequência absoluta de unidades de registro que puderam ser identificadas em cada uma das situações investigadas (trilha tradicional e trilha gamificada). A partir da Figura 3 é possível perceber que a proporção de unidades de registro na EMA (461) foi significativamente superior às registradas na trilha tradicional (106), o que remete ao fato de que na EMA os participantes estiveram verbalmente mais ativos e, portanto, engajados nesse sentido. É preciso levar em consideração, porém, dados relevantes para a leitura desses resultados, como é o fato de a atividade gamificada ter durado aproximadamente $38 \%$ a mais que a tradicional, ao passo que a atividade tradicional contou com mais que o dobro de participantes da atividade gamificada.

Figura 3 - Frequência absoluta de unidades de registro identificadas na EMA e na atividade tradicional em trilhas do PEMG

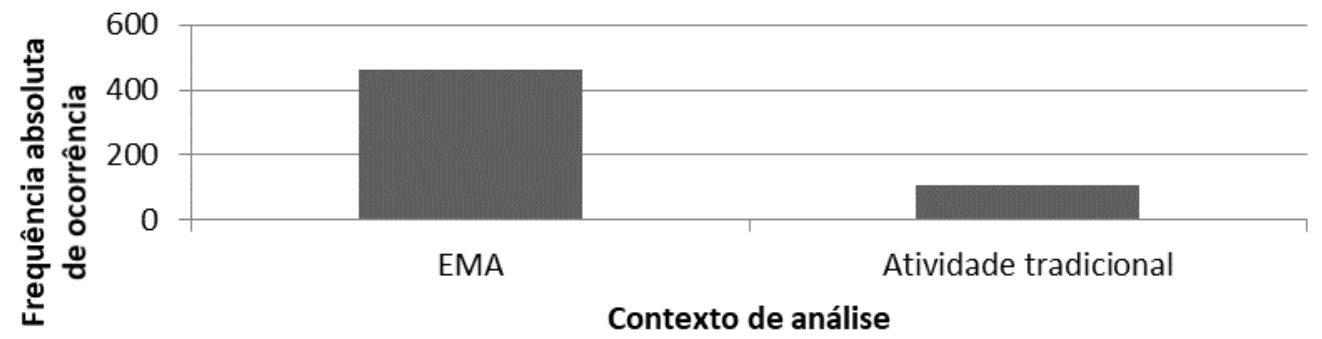

Fonte: SILVA-MEDEIROS (2016b).

Das unidades de registro da atividade gamificada, 325 ou $70 \%$ do total foram indiciadas como comportamento de jogar (Categoria 1), 372 ou $81 \%$ como comportamentos que mantêm o comportamento de jogar (Categoria 2), 421 ou 91\% como comportamentos relacionados aos objetivos da Educação Ambiental (Categoria 3) e 227 ou 44\% como comportamentos relacionados aos objetivos específicos da Interpretação Ambiental (compreensão, sensibilidade e responsabilidade ambientais) (Categoria 3'). Em análise desses números e proporções em diferentes unidades de contexto (momentos) da atividade, contudo, percebeu-se que os comportamentos de jogar foram mais frequentes no início da atividade, enquanto os relativos aos objetivos específicos da Interpretação Ambiental (IA) foram nulos num primeiro momento e aumentaram gradualmente no decorrer da trilha (ver Figuras 4 e 5). 
Figura 4 - Proporção de ocorrência do comportamento de jogar nas unidades de contexto da atividade gamificada

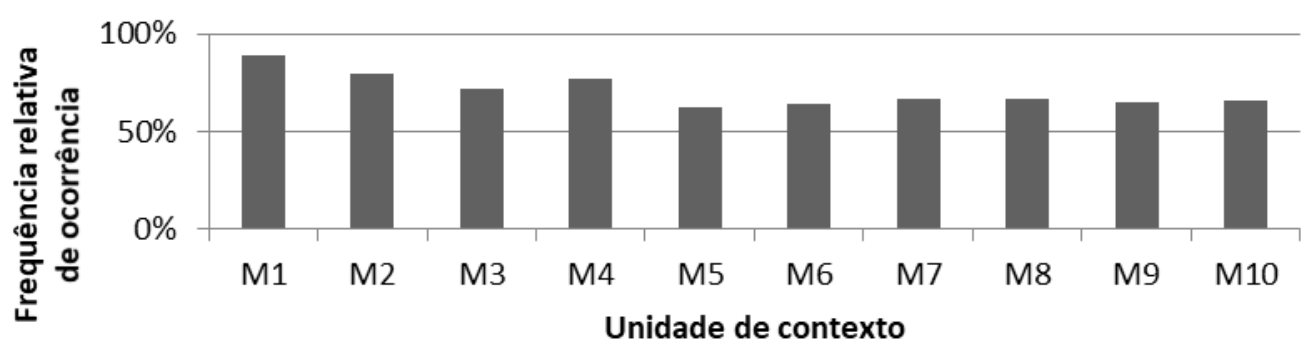

Fonte: SILVA-MEDEIROS (2016b).

Figura 5 - Proporção de ocorrência dos comportamentos relacionados aos objetivos da Interpretação Ambiental nas unidades de contexto da atividade gamificada

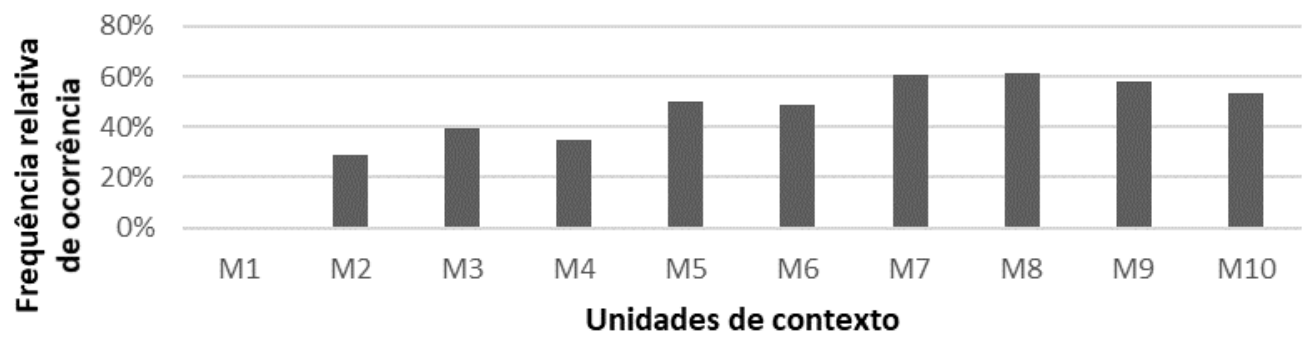

Fonte: SILVA-MEDEIROS (2016b).

Embasando-se em alguns dos primeiros e mais expressivos trabalhos publicados na área (BARANOWSKI, 2008; BEZA, 2011; DETERDING, 2011; DONG et al., 2012; HAMARI; KOIVISTO; SARSA, 2014; KAPP, 2012; LEE; HAMMER, 2011; MORFORD et al., 2014; RUCHTER; KLAR; GEIGER, 2010; SU; CHENG, 2013; ZICHERMANN; GUNNINGHAM, 2011), a função da gamificação na educação é motivacional, aumentando o engajamento do sujeito sem que se percam as qualidades educacionais da atividade. Para que isso ocorra, no entanto, os elementos da gamificação não podem "roubar a cena" de modo a suplantar o conteúdo de ensino, a exemplo do que foi relatado por Ruchter, Klar e Geiger (2010) e Rogers et al. (2005), sobre a distração causada na relação com os mobiles, ou mesmo levar a um quadro de dependência, como o citado por Lee e Hammer (2011) e Dong et al. (2012), em relação às recompensas e ao layout da atividade gamificada.

No caso desta pesquisa, é possível concluir que os elementos da gamificação podem, sim, ter colaborado para alguma distração dos participantes em relação aos objetivos educacionais, contudo, como sugerem Ruchter, Klar e Geiger (2010), tal distração pode ser causada pelas dificuldades operacionais dos participantes, o que se minimiza conforme vão desenvolvendo competências para lidar com tais elementos e permite que sua atenção seja voltada para outros fatores (educacionais, no caso). Situação, essa, evidenciada pelo aumento gradativo de respostas relacionadas aos objetivos específicos da Interpretação Ambiental ao longo da atividade (ver Figura 5). 
Em relação à trilha tradicional, não foi possível evidenciar a ocorrência de uma significativa parte dos índices de análise identificados por meio da EMA, até porque a atividade não foi planejada para conter elementos de gamificação, o que se observa na falta de ocorrências de subcategorias do comportamento de jogar (Categoria 1) e da manutenção desses comportamentos (Categoria 2) (ver Figura 6). O que chama a atenção, no entanto, é a ocorrência dos comportamentos relativos aos objetivos da Educação Ambiental (Categoria 3), cujas proporções de ocorrência de compreensões (Subcategoria 3A) e de sensibilidades (Subcategoria 3B) em relação à de competências (Subcategoria 3D) se inverte na atividade gamificada (ver Figura 7).

Figura 6 - Proporção de ocorrência das categorias de análise na atividade tradicional em trilhasdo PEMG

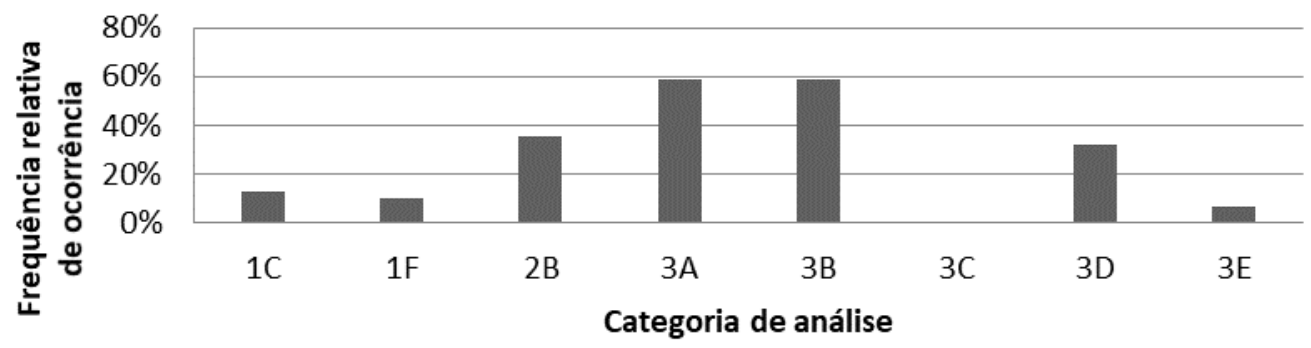

A Subcategoria 1 C refere-se ao controle de regras, instruções e barreiras da atividade; a Subcategoria $1 F$ refere-se ao início livre de persuasão na atividade; a Subcategoria $2 B$ refere-se às interações interpessoais; a Subcategoria $3 A$ refere-se aos comportamentos relacionados à compreensão ambiental; a Subcategoria $3 B$ refere-se aos relacionados à sensibilidade ambiental; a Subcategoria $3 C$ refere-se aos relacionados à responsabilidade ambiental; a Subcategoria 3D refere-se aos relacionados à competência ambiental e a Subcategoria $3 E$ refere-se aos relacionados à cidadania ambiental.

Fonte: SILVA-MEDEIROS (2016b).

Figura 7 - Proporção de ocorrência das categorias dos comportamentos relacionados aos objetivos da Educação Ambiental na Categoria 3 na atividade gamificada

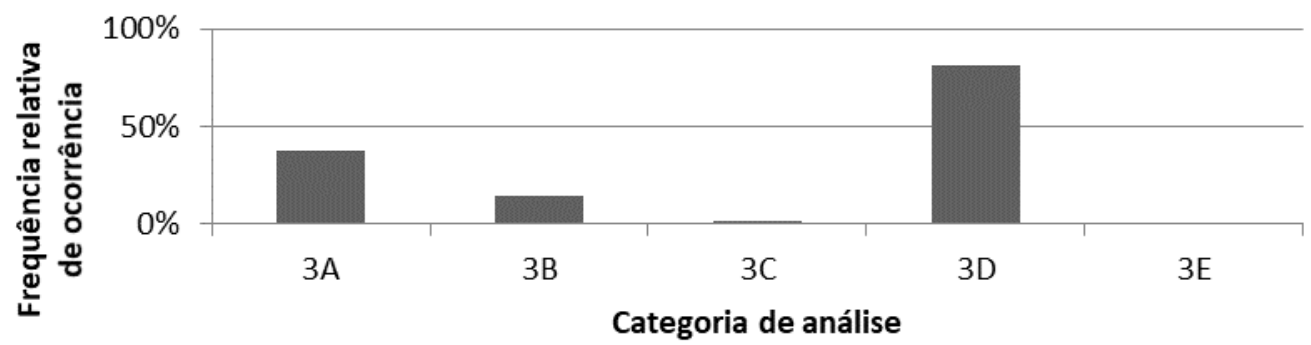

A Subcategoria $3 A$ refere-se à compreensão ambiental; a Subcategoria $3 B$ refere-se à sensibilidade ambiental; a Subcategoria $3 C$ refere-se à responsabilidade ambiental; a Subcategoria $3 D$ refere-se à competência ambiental e a Subcategoria $3 E$ refere-se à cidadania ambiental.

Fonte: SILVA-MEDEIROS (2016b).

Percebe-se, portanto, que a atividade gamificada foi capaz de estimular uma frequência relativa de competências (Subcategoria 3D) significativamente superior em relação à atividade tradicional, além de que a frequência absoluta também foi notadamente 
superior, com apenas 34 ocorrências na atividade tradicional ante 343 na atividade com a EMA. Em relação às compreensões (Subcategoria $3 \mathrm{~A}$ ), a frequência absoluta também foi significativamente superior na atividade gamificada, com 159 ocorrências diante de 64 na atividade tradicional. A sensibilidade ambiental (Subcategoria 3B) teve ocorrência equivalente em ambas, expressões de responsabilidade ambiental (Subcategoria 3C) só foram indiciadas em seis unidades de registro presentes na atividade gamificada e a cidadania teve sete ocorrências na atividade tradicional, mostrando-se nula na EMA.

Munro, Morrison-Saunders e Hughes (2008) explicitam que a Interpretação Ambiental, no limitado espaço físico e de tempo que ocupa, não é eficiente no desenvolvimento de competências e cidadania ambiental dos participantes, o que de fato se pôde notar em análise da trilha tradicional do PEMG. A alta ocorrência de competências na atividade gamificada, porém, demonstra que as tarefas apresentadas pela EMA foram suficientes para mobilizar diversos procedimentos, métodos e estratégias relevantes aos objetivos educacionais da Educação Ambiental.

Para além dos objetivos da Educação Ambiental, a Interpretação Ambiental deve ser uma atividade recreativa (PROJETO DOCES MATAS , 2012), o que leva ao planejamento de atividades contendo o mínimo possível de elementos que lembrem a formalidade, tais como regras, instruções e barreiras. Apesar, contudo, de a gamificação se diferenciar em meio ao universo lúdico pela expressiva apresentação de regras, instruções e barreiras (DETERDING et al., 2011), as análises da participação dos visitantes do PEMG na EMA não levaram a quaisquer evidências de que a manutenção do engajamento dos participantes na atividade tenha sido prejudicada por esses elementos da gamificação, pois os participantes mantiveram-se ativos nas tarefas da atividade do início ao fim. Esse fato não foi percebido na atividade tradicional em trilhas, até em razão da qualidade de algumas unidades de registro em que os participantes reclamavam de indisposição e impaciência para continuar a atividade até o fim (mesmo que ela tenha durado menos que a gamificada).

No que se refere aos comportamentos estimulados por elementos que atuam sobre a manutenção do comportamento de jogar (Categoria 2), na atividade gamificada foi percebida a ausência de ocorrências de comportamentos estimulados pela história da EMA (Subcategoria 2D) (ver Figura 8).

Figura 8 - Proporção de ocorrência das categorias dos comportamentos relevantes na manutenção do comportamento de jogar na Categoria 2 na atividade gamificada

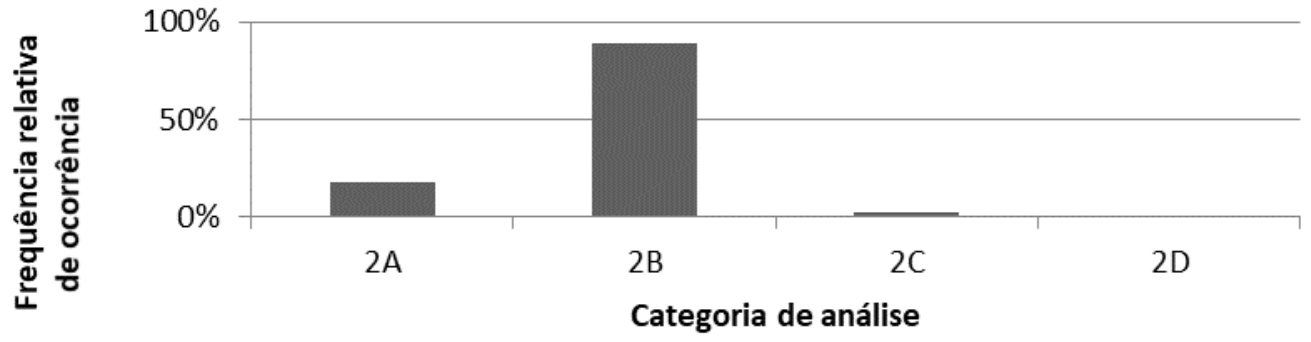

A Subcategoria $2 A$ refere-se a respostas dos participantes a elementos novidadeiros da EMA; a Subcategoria $2 B$ refere-se a interações interpessoais entre os participantes e deles com o guia da atividade; a Subcategoria $2 \mathrm{C}$ refere-se à evolução de estratégias e a Subcategoria $2 D$ refere-se a comportamentos relacionados à história da EMA. 
A história da EMA foi apresentada de modo claro e objetivo pelo guia no início da atividade e retomada ao final dela, mas, conforme demonstra Thorndyke (1977) e explica Ham (1992), verbalizar de forma clara e objetiva o tema da Interpretação Ambiental também no entremeio da comunicação pode vir a constituir uma estratégia efetiva. Assim, é possível considerar a relevância de se apresentar a história ou o tema da EMA de forma clara e objetiva também no decorrer da atividade e de modo que as falhas na comunicação do guia ou monitor da atividade com a audiência possam ser supridas por um texto escrito e recursos audiovisuais.

Apesar da ausência de evidências de eventos comportamentais controlados pela história da EMA, os participantes pareceram responder aos elementos de manutenção do comportamento de jogar (Categoria 2) durante toda a atividade (ver Figura 9), principalmente em relação à interação com outros jogadores (Subcategoria 2B), cuja proporção de respostas parece ser significativamente superior às demais subcategorias (ver Figura 8).

Figura 9 - Proporção de ocorrência dos comportamentos relevantes na manutenção do comportamento de jogar (Categoria 2) nas unidades de contexto da atividade gamificada

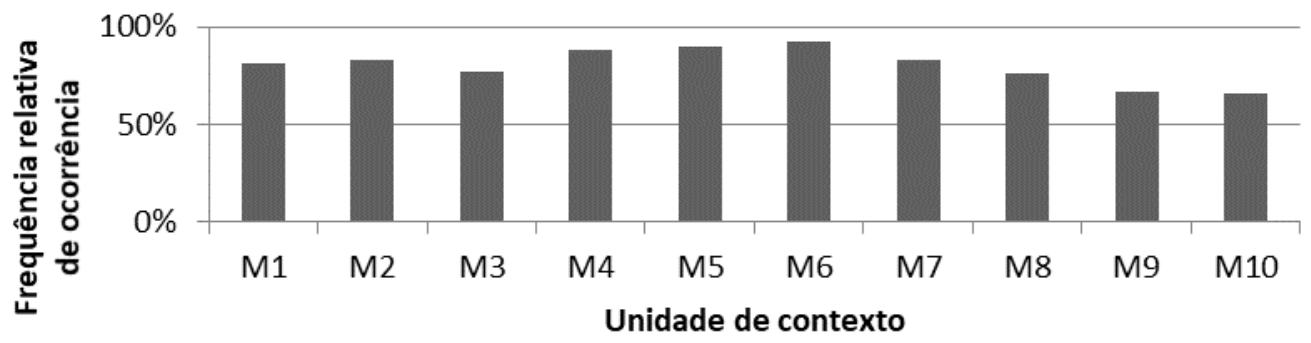

Fonte: SILVA-MEDEIROS (2016b).

As diferentes funções dos participantes na EMA parecem ter influenciado no âmbito de suas relações interpessoais. Com 330 ocorrências na atividade gamificada contra apenas 38 na atividade tradicional, é possível afirmar que essa foi uma contribuição no sentido educacional à trilha interpretativa, uma vez que, conforme explica Skinner (1972), o comportamento verbal é aprendido por meio das consequências provindas da comunidade. Sendo os objetivos específicos da Interpretação Ambiental relacionados principalmente a formas de comportamento verbal, é provável que essa interação tenha influenciado na significativa diferença de ocorrência de comportamentos relativos a compreensões ambientais entre as duas atividades.

Assim como a evolução de estratégias desenvolvidas (Subcategoria 2C) mostrou-se tímida na atividade gamificada (ver Figura 8), o desenvolvimento de novas estratégias (Subcategoria 1E) teve frequência relativa decrescente do início ao fim da atividade (ver Figura 10). Essa observação pode ser atribuída ao fato de os participantes terem aprendido um conjunto suficiente de estratégias para lidar com a EMA logo no início da atividade, e que as novidades apresentadas pela atividade gamificada no decorrer de seu progresso não foram suficientes para estimular o desenvolvimento ou a evolução de estratégias na mesma proporção que no início. 
Figura 10 - Proporção de ocorrência do desenvolvimento de estratégias nas unidades de contexto da atividade gamificada

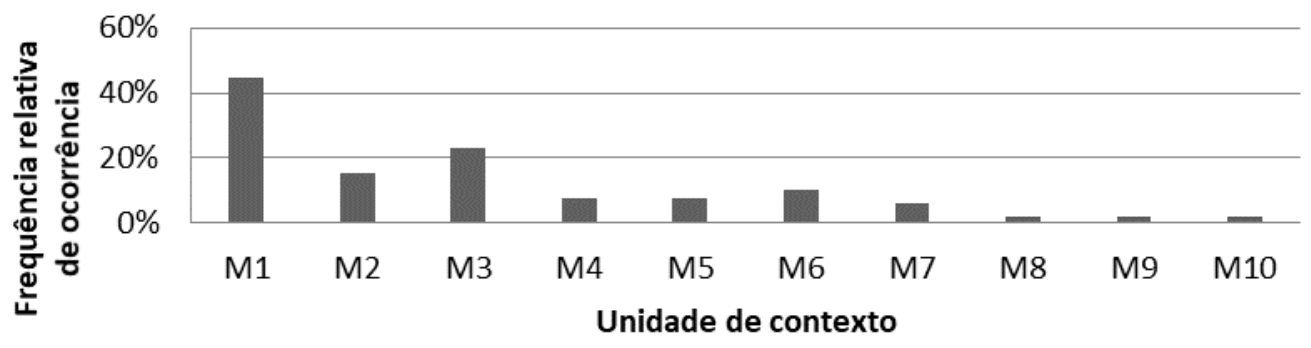

Fonte: SILVA-MEDEIROS (2016b)

Ao se analisar as unidades relacionadas aos impactos diretos das ações do participante nos efeitos e resultados da EMA (Subcategoria 1A), percebe-se que as dificuldades relativas aos elementos próprios da gamificação dão lugar às dificuldades enfrentadas na interpretação do ambiente visitado (tarefa necessária para o avanço no jogo) e pela falta de atenção dos participantes nos momentos finais da atividade. Assim, é possível concluir que o aprendizado sobre a Biologia, a Ecologia e os aspectos socioculturais do local visitado a partir da codificação técnico-científica é algo que pode, em razão do perfil dos participantes, ser dificultoso e modificar ou aumentar de modo inesperado a complexidade das tarefas numa atividade gamificada de IA. Por esse motivo, importa que os participantes sejam capazes de perceber eventos probabilísticos da atividade (Subcategoria 1D), de modo que suas dificuldades não gerem ansiedade e que estejam prontos para lidar com a elaboração de novas estratégias de aprendizagem. Em todo caso, as características singulares do sítio da IA incrementam um elevado grau de incerteza à atividade gamificada, pois, composto por um sistema vivo e dinâmico e fora do comum aos participantes, é difícil prever quais seres, objetos e situações surgirão no decorrer do caminho. Sendo o grau de incertezas e riscos elevados um aspecto potencial na estimulação de comportamentos de fuga e esquiva ${ }^{9}$ (SKINNER, 2003), apesar de a gamificação contar com elementos que estimulem a elaboração de estratégias pelo aumento no nível de dificuldade e complexidade das tarefas, em atividades pervasivas como é o caso da EMA - torna-se relevante que se leve em consideração as dificuldades e incertezas que o mundo "real" já oferece aos participantes.

\section{CONCLUSÃO}

As influências identificadas por meio das análises aqui descritas foram diversas. Em seus pormenores, esses estudos possibilitaram a observação de muitos resultados que puderam e podem ser explorados para além do que foi apresentado neste conci-

Na Análise do Comportamento, são comportamentos que promovem o desengajamento. 
so trabalho (ver em MEDEIROS-SILVA, 2016b). Aqui, foram apresentados os resultados que pareceram mais significativos no sentido dessa influência e que remetem a algumas conclusões importantes.

Sabe-se que a Interpretação Ambiental é uma atividade que, por fundamento, promove o engajamento e tem caráter altamente lúdico, no entanto, pela diversidade de perfis de público a que atende, os graus de engajamento podem mudar consideravelmente entre os participantes. No caso da investigação aqui descrita, contudo, tem-se uma evidência de que a gamificação pode vir a contribuir nesse sentido. Os jogos e, consequentemente, seus elementos, parecem surtir efeito motivacional em um amplo espectro de perfis de sujeitos e, por esse meio, os participantes parecem ficar mais ativos e engajados em atividades gamificadas do que em métodos mais tradicionais e passivos de execução.

Referindo-se à EMA, em específico, foi possível notar que o aprendizado de competências depende exclusivamente de como a atividade se desenvolve, de que maneira os participantes percebem os resultados de suas ações e de como as tarefas evoluem; e que essas competências podem fazer parte dos objetivos educacionais da atividade, a depender de como as tarefas são planejadas e do grau de pervasividade que estabelecem com o meio. Graus de incerteza, contudo, devem ser devidamente medidos na gamificação, ao passo que o mundo "real" já apresenta seus próprios problemas. Ademais, pode-se considerar que o planejamento das interações dos participantes entre si e com outros atores é favorecido pelos elementos da gamificação. Sejam competitivos ou cooperativos, os elementos que estimulam a interpessoalidade parecem colaborar para uma produção de conhecimentos mais eficaz do que quando os participantes agem sem haver tarefas que estimulem esse tipo de interação.

Por fim, esperamos que este trabalho venha contribuir com a evolução das áreas da gamificação, da Educação Ambiental e da Interpretação Ambiental. No âmbito científico, a expectativa é que o trabalho seja fecundo o suficiente para fundamentar pesquisas que tenham a pretensão de colaborar com a questão aqui exposta e o objetivo dela advindo. Em todo caso, consideramos que os resultados apresentados possam ser motivadores aos designers, educadores e guias, para que passem a adotar elementos da gamificação em seus planejamentos e práticas. Com base nos estudos realizados, nas experiências vivenciadas e nos resultados obtidos, formamos a concepção de que práticas gamificadas podem vir a surpreender aqueles que procuram melhorar suas práticas de ensino por meio do engajamento e da participação ativa dos aprendizes.

\section{REFERÊNCIAS}

BARANOWSKI, T. et al. Playing for real: video games and stories for health-related behavior change. American Journal of Preventive Medicine, v. 34, n. 1, p. 74-82, 2008. Disponível em: https://www.sciencedirect.com/science/article/pii/S0749379707006472. Acesso em: 17 set. 2019.

BARDIN, L. Análise de conteúdo. Tradução Luís Antero Reto e Augusto Pinheiro. Lisboa: Edições 70, 1977. BAUM, W. M. Compreender o behaviorismo: ciência, comportamento e cultura. Tradução Maria Teresa Araujo Silva et al. Porto Alegre: Artes Médicas Sul, 1999.

BEZA, O. Gamification - How games can level up our everyday life, 2011. Disponível em: https:// www.semanticscholar.org/paper/Gamification-\%E2\%80\%93-How-games-can-level-up-our-everyday-Beza/573a3fdb80521dc599b98cc1d4eda76562c9e379. Acesso em: 28 ago. 2020. 
BRASIL. Base Nacional Comum Curricular. Brasília: MEC, 2017. Disponível em: http://basenacionalcomum.mec.gov.br/images/BNCC_EI_EF_110518_versaofinal_site.pdf. Acesso em: 17 set. 2019.

BRASIL. Diretrizes Curriculares Nacionais para Educação Básica. Brasília: MEC; SEB; Secadi; CNE, 2013. Disponível em: http://portal.mec.gov.br/docman/julho-2013-pdf/13677-diretrizes-educacao-basica-2013-pdf/file. Acesso em: 17 set. 2019.

BRASIL. Parâmetros Curriculares Nacionais. Brasília: MEC; SEF, 1998. Disponível em: http://portal.mec. gov.br/component/content/article?id=12640: parametros-curriculares-nacionais-10-a-4o-series. Acesso em: 17 set. 2019.

BRASIL. Programa Nacional de Educação Ambiental. 3. ed. Brasília: Ministério do Meio Ambiente, 2005. Acesso em: https://www.mma.gov.br/estruturas/educamb/_publicacao/20_publicacao12012009114423. pdf. Acesso em: 17 set. 2019.

COLL, C. et al. Os conteúdos da reforma: ensino e aprendizagem de conceitos, procedimentos e atitudes. Porto Alegre: Artes Médicas, 2000.

CHIESA, M. Radical Behaviorism: The philosophy and the science. Boston: Autors Cooperative, 1994.

DETERDING, S. et al. From Game Design Elements to Gamefulness: Defining "Gamification". MindTrek, Tampere, Finlândia, 2011. Disponível em: https://dl.acm.org/citation.cfm?id=2181040. Acesso em: 17 set. 2019.

DONG, T. et al. Discovery-based Games for Learning Software. In: Proceedings of the 2012 ACM annual conference on Human Factors in Computing Systems. Austin, Texas, EUA, 2012. Disponível em: https:// dl.acm.org/citation.cfm?id=2208358. Acesso em: 17 set. 2019.

FRANCO, M. L. P. B. Análise de conteúdo. 3. ed. Brasília: Liber Livro, 2008.

HAM, S. Environmental Interpretation: a practical guide for people with big ideas and small budgets. Colorado, EUA: North American Press, 1992.

HAMARI, J.; KOIVISTO, J.; SARSA, H. Does Gamification Work? - A Literature Review of Empirical Studies on Gamification. In: Hawaii International Conference on System Science, 47, [S.I.], p. 3.025-3.034, 2014. Disponível em: https://www.researchgate.net/profile/Michael_Armstrong6/post/What_empirical_evidence_is_there_for_various_gamification_techniques/attachment/59d61dcb79197b8077979ce0/AS:27 3513875738624@1442222197132/download/2014-hamari_et_al-does_gamification_work.pdf. Acesso em: 17 set. 2019.

KAPP, K. M. The gamification of learning and instruction: game-based methods and strategies for training and education. São Francisco, CA, USA: John Wiley \& Sons, 2012.

LEE, J. J.; HAMMER, J. Gamification in Education: What, How, Why Bother? Academic Exchange Quarterly, v. 15, n. 2, 2011. Disponível em: https://www.researchgate.net/publication/258697764_Gamification_in_ Education_What_How_Why_Bother. Acesso em: 17 set. 2019.

MATOS, M. A. Comportamento governado por regras. Revista Brasileira de Terapia Comportamental $e$ Cognitiva, [S.I.], v. 3, n. 2, p. 55-61, 2001. Disponível em: http://www.usp.br/rbtcc/index.php/RBTCC/article/view/135. Acesso em: 17 set. 2019.

MORAES, R.; GALIAZZI, M. do C. Análise textual discursiva. Ijuí: Editora Unijuí, 2007. 224 p.

MORFORD, Z. H. et al. Gamification: The intersection between Behavior Analysis and Game Design Technologies. Behavior Analyst, n. 37, p. 25-40, 2014.

MUNRO, J. K.; MORRISON-SAUNDERS, A.; HUGHES, M. Environmental Interpretation Evaluation in Natural Areas. Journal of Ecotourism, v. 7, n. 1, 2008. Disponível em: https://www.tandfonline.com/doi/ abs/10.2167/joe137.0. Acesso em: 17 set. 2019.

PROJETO DOCES MATAS. Manual de Introdução à Interpretação Ambiental. Belo Horizonte: Grupo Temático de Interpretação Ambiental, 2002.

ROGERS, Y. et al. Ubi-learning integrates indoor and outdoor experiences. Communications of the ACM, v. 48, n. 1, p. 55-59, 2005. Disponível em: http://www.academia.edu/download/5252223/10.1.1.60.1361. pdf. Acesso em: 17 set. 2019.

RUCHTER, M.; KLAR, B.; GEIGER, W. Comparing the effects of mobile computers and traditional approaches in environmental education. Computers \& Education, n. 54, 2010. Disponível em: https://www.sciencedirect.com/science/article/pii/S0360131509002954. Acesso em: 17 set. 2019.

SILVA, D. M. da. A caracterização da interpretação ambiental pelo conteúdo das mensagens: análise da atividade de um guia do Parque Estadual Mata dos Godoy (Londrina/PR). 2012. 92 p. Dissertação (Mestrado em Ensino de Ciências e Educação Matemática) - Universidade Estadual de Londrina, Londrina, 2012. 
SILVA, D. M. da. Um estudo da Interpretação Ambiental do Parque Estadual Mata dos Godoy: análise das mensagens proferidas por uma guia iniciante. 2011. 71 p. Trabalho de Conclusão de Curso (Especialização em Análise e Educação Ambiental em Ciências da Terra) - Universidade Estadual de Londrina, Londrina, 2011.

SILVA-MEDEIROS, D. M. da. Expedição ao meio ambiente: gamificação da trilha interpretativa do Parque Estadual Mata dos Godoy. Revista de Ensino de Biologia da Associação Brasileira de Ensino de Biologia, $\mathrm{n}$. 9, p. 619-630, 2016a.

SILVA-MEDEIROS, D. M. da. Gamificação e interpretação ambiental: uma experiência em trilha ecológica. 2016. 169 f. Tese (Doutorado em Ensino de Ciências e Educação Matemática) - Centro de Ciências Exatas, Universidade Estadual de Londrina, Londrina. 2016b.

SILVA-MEDEIROS, D. M. da; HAYDU, V. B. Interpretação Ambiental à luz dos princípios da Análise do Comportamento: contribuições para Educação Ambiental. Perspectivas em análise do comportamento, [S.I.], v. 9, n. 1, p. 43-59, 2018. Disponível em: https://www.revistaperspectivas.org/perspectivas/article/ view/453. Acesso em: 17 set. 2019.

SKINNER, B. F. Ciência e comportamento humano. Tradução João Carlos Todorov e Rodolfo Azzi. 11. ed. São Paulo: Martins Fontes, 2003.

SKINNER, B. F. Tecnologia do ensino. Tradução Rodolpho Azzi. São Paulo: Herder; Ed. da Universidade de São Paulo, 1972.

SMITH, J. C. Environment and Education: a view of a changing scene. Environmental Education Research, v. 12, n. 3-4, p. 247-264, jul./set. 2006. Disponível em: https://www.tandfonline.com/doi/ abs/10.1080/1350462950010101. Acesso em: 27 set. 2019.

SU, C.; CHENG, C. A Mobile Game-based Insect Learning System for improving the learning achievements. Procedia - Social and Behavioral Sciences, n. 103, p. 42-50, 2013. Disponível em: https://www.sciencedirect.com/science/article/pii/S1877042813037506. Acesso em: 17 set. 2019.

THORNDYKE, P. W. Cognitive structures in comprehension and memory of narrative discourse. Cognitive Psychology, v. 9, n. 1, p. 77-110, 1977. Disponível em: https://www.sciencedirect.com/science/article/ pii/0010028577900056. Acesso em: 17 set. 2019.

ZABALA, A. A prática educativa: como ensinar. Porto Alegre: Artmed, 1998.

ZICHERMANN, G.; CUNNINGHAM, C. Gamification by design: Implementing game mechanics in web and mobile apps. "O’Reilly Media, Inc.", 2011. Disponível em: https://books.google.com.br/books?hl=p$t-B R \& \mid r=\& i d=z Z c p u M R p A B 8 C \& o i=f n d \& p g=P R 7 \& d q=G a m i f i c a t i o n+b y+d e s i g n:+I m p l e m e n t i n g+$ game+mechanics+in+web+and+mobile+apps\&ots=UuQc7-w83c\&sig=8wQJq5YhXzuBIbnrXJFSNQgWMjl. Acesso em: 17 set. 2019. 